\title{
LA-5449-MS
}

INFORMAL REPORT

\section{Simulation of Turbulence in Fireballs}


This report was prepared as an account of work sponsored by the United States Government. Neither the United States nor the United States Atomic Energy Commission, nor any of their employees, nor any of their contractors, subcontractors, or their employees, makes any warranty, express or im. plied, or assumes any legal liability or responsibility for the accuraey, com. pleteness or usefulness of any information, apparatus, product or process dis. closed, or represents that its use would not infringe privately owned rights.

In the interest of prompt distribution, this LAMS report was not edited by the Technical Information staft.

Printed in the United Sutes of Ametica. Available trom

National Technical Inlormation Service

U. S. Department of Commerce

5285 Port Roval Poad

Springlield. Virginia 23151

Price: Printed Copy S4.00 Mirpoliche $\$ 1.45$ 


\title{
LA.5449-MS
}

INFOAMAL REPORT

UC.34

ISSUED: November 1973

\section{Simulation of Turbulence in Fireballs}

by

\author{
Hans M. Ruppel \\ Richard A. Gentry \\ Bart J. Daly
}

This work supported by the Defense Advanced Research Projects Agency and the Defense Nuclear Agency.

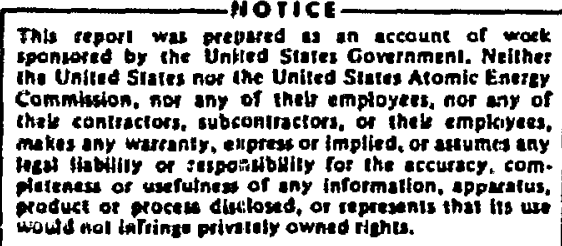

This reporl wat prepsed a an accoune of wokk the United sia the United sines corernm Commision. not any of inty employers, nor eny of that contractors, subcohifactors, of thet emplayees,

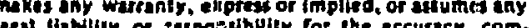
Aliteness of usefutnas or any information, sppurafus.

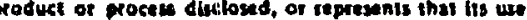
wowls mal bafringe pringatr owned rights. 
The ALE cechnique is applice to the calculation of a small yfeld, low altitude nuclear explosion. Then artificial diffusion effects caused by numerical errors are minimlzed, the fireball rises too rapldly, reaching an altitude in excess of that which 1s observed. This suggests that curbulent diffusion and entrainment ray be Important. Hence, we have added a turbulence nodel to later calculations of the eireball dyaanics. Th1s report deBcribes acme of the more important features of our calculational cechnique and discusses the curbulence model in some detail. Prellminary resules for a set of curbulence parameters and a particular low altitude firebail are presented.

\section{INTRODUCTION}

Prezious efforts to calculate the dynamics of fireballs have falled to yicld a zood compazison with the avallable daca. Thls repert discusses efforts to narrow the discrepancy between numerical simulations and empirical information. An aspect which is examined in some detall is the effect of including turbulence in the calculation.

The current work emphnsizes the late time behavior (post-torus formation), when buoyancy forces and atmospheric stratification cause large fircball deformations. The primary purpose of this effore is to develop the capability to predict chose aspects of atwospher lc nucleaz explostons that reflect on the performance of both of fensive and defensive toissile systems. In order to accorplish this purpose. 1t is necessary to detcroine:

(1) The size, shape, and rise race of the f1rebal1.

(2) The temperature, dens1ty, pressure, and velocicy fields. These are parefcularly Imporcane for decermining the effects on misslles that fly chrough disturbed fireball regions.

(3) The effects of curbulence. Turbulence can alter the gross behavior of the fireball via enhanced mixing, which smears out differences in temperature and density. Smail-scale turbulent fluctuafions are also of interest, since they can affect radat elutter recurn.

The intelal emphasis of the LASL-DNA effort centered on the development of a nev computer proBram, Yaqui, which perates a mueti more acturate calculation of the mean flow hydrodymatic behavior of buoyanc fircbalis. The additional DARPA funding has made posstble che expanston of this cffort to develop a turbulence model and to incorparate chis into the basic YaQUI program. This report will deseribe the LASL fircball curbulence rodeling efforta made posstble by che DARPA funds. Four aspects of our recent work are discussed.

(1) Improvenenes made in the basic raguz hydrodynamics pregram used to calculate turbulcne fireball behavior.

(2) The curbulence model equations used to compute the turbulence field.

(3) The parameters that must be decermined to complete the turbulence madel.

(4) The effeces of turbulence on firebill behavior as indleated by sume preliminary calculat loms. 
II. TTIE BASIC HYDRODYNAMICS PROGRAM

In the present model the turbulence fleld generated in a fireball is completely determined by the properties of the mean flow-field. Thus, no attempt to Implement the turbulence model can be successful unless the dynamics of the mean flow is falthfully represented. This implies that the development and Incorporation of a turbulence model into the YAQUI fireball dynamics program must include a careful treatment of the nonturbulent hydrodynamics.

The YAQUI code used in tinis study is a modified verstion of the ALE technique ${ }^{2}$ for hydrodynamic studies. This technique is well qualifled for fireball calculations, since it permits great flexibility in mesh resolution and mesh motion. In the early, developmental stages of this method, the calculation al grid consisted of rectangular cells of variable size: small cells for high resolution in the active reglons of the fireball and much larger cells fil the peripheral areas. Although it was possible to maintain sharp temperature gradzents to late time with this resolution, a discrepancy between the calculated and the observed rise history existed. To reduce this discrepancy, a Lagranglan-like rezone ${ }^{3}$ procedure was 1ncorporated. This Improved the comparison of rise rate with experiment. The reason for this Improvement is that the rezone procedure minimizc: the relative motion of the $\mathrm{grid}$ and the fluid, and hence reduces the diffusive truncation errors inherent in the convection process. 4

The grid is moved according to

$\vec{x}_{1, j}^{n+1}=\vec{x}_{1, j}^{n}+\vec{u}_{1, j}^{L} \delta t+f\left(\vec{x}_{1, j}^{n}-\left\langle\vec{x}^{n}>\right)\right.$, where $\chi_{1, j}^{n}$ is the radius vector at time level $n$, $\vec{v}_{i, j}^{L}$ is the fluid velocity of vertex $(1, j)$, f is a varlable relaxation coefficient, and $\left\langle\bar{x}^{n}>\right.$ is the average value of the coordinates of the four cell vert ices nearest to $\overline{\mathrm{k}}_{i, j}^{n}$. Figure 1 displays a typical mesh at a time of 15 scc fuxtaposed with a plot of the temperature contours.

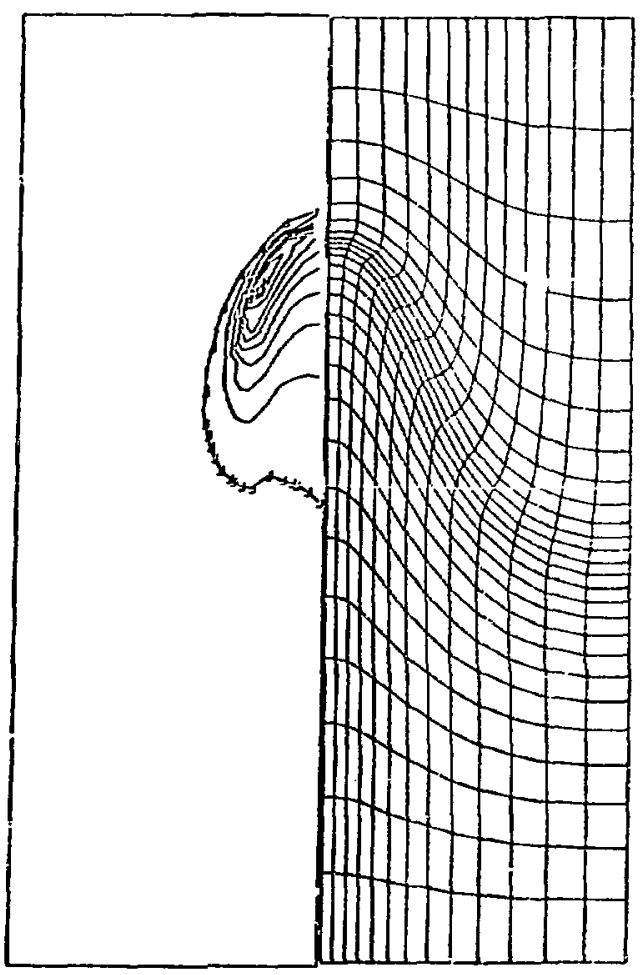

51g. 1. Juxtaposition of Lagranglan-like calculation mesh with contours of 1 sotherms at $15 \mathrm{sec}$ after burst for a typical firebal1.

This figure 1llustrates the manner in which the mesh lines follow the contours and the smaller cells collect in the region of large gradients. The correspondence among grid lines and temperature and densicy contours implies a minimal flux of fluid and hear through the cells and hence a relatively nondiffusive calculation. The reason for this is that the diffusion in the convective phase is proportional not only to the gradient of the quautity being convected but aiso to the relative velocity of grid and flutd and the cell dimenston in the direction of the relative velocity. As is evident in Fig. 1, the present rezoning algoritha allows small cells to follow the region of maximum temperacure gradient while holding the fluxing velocity to a minimur. 
III. THE TURBULENCE MODEL

To model the effects of turbulence, we have adopted the turbulence transport approach of Daly and harlow. 5 with this representation, the contribution of turbulence to mean flow dynamics appears In the form of second-order moments of fluctuating quantities in the conservation squations of fluid flow. Sone means must be provided for interpreting these second-order correlations in order to close the system of equations. The approach used has been to derlve transport equations for these correlations directly from the fluctuating momentum equations. Approximations are introduced for the higher-order moments that appear in these equations, and then the entire system of equations, for mean and fluctuating quantities, is solved simultaneously.

Begin by asguming that all of the flow variables can be uritten as the sum of mean and fluctuating parts, thus:

$$
\begin{aligned}
& \rho=\bar{p}+\rho^{\prime}, \quad \text { (density) } \\
& u_{1}=\bar{u}_{1}+u_{1}^{\prime}, \quad \text { (veloc1ty) } \\
& \rho I=\overline{\rho I}+(\rho I)^{\prime}, \quad \text { (internal energy), }
\end{aligned}
$$

where the overtiar indicates an ensemble average. The ensemble average of a single fluctuating quantity 111 vanish by definition but the average of products of fluctuating quantities will, in general, not vanish. Thus,

$\overline{u_{1}^{\prime}}=0, \overline{u_{1}^{\prime} u_{j}^{\prime}} \neq 0$, etc.

The expressions (1) - (3) are substicuted into the conservation equations and these equations averaged to give:

mass equetion -

$\frac{\partial p}{\partial t}+\frac{\partial}{\partial x_{j}}\left(\vec{p} \bar{u}_{j}+\overline{p^{\prime} u_{j}^{\prime}}\right)=0$

monentum equation -

$\frac{\partial}{\partial t}\left(\bar{\rho} \bar{u}_{1}+\overline{\rho^{\prime} u_{1}^{\prime}}\right)+\frac{\partial}{\partial x_{j}}\left(\bar{\rho} \bar{u}_{1} \bar{u}_{j}+\bar{u}_{1} \overline{\rho^{\prime} u_{j}^{\prime}}+\bar{u}_{j} \overline{\rho^{\prime} u_{1}^{\prime}}\right.$

$$
\left.+\overline{p u_{1}^{\prime} u_{j}^{\prime}}\right)-\frac{\partial \bar{p}_{11}}{\partial x_{j}}+\bar{p} g_{1} \text {. }
$$

Internal energy equation -

$$
\frac{\partial}{\partial t} \overline{\rho I}+\frac{\partial}{\partial x_{j}}\left(\overline{\rho I} \bar{u}_{j}+\overline{\rho u_{j}^{\top} I^{\top}}\right)=\bar{p}_{1 j} \frac{\partial \bar{u}_{i}}{\partial x_{j}}+\overline{p_{i j}^{\prime} \frac{\partial u_{i}^{\top}}{\partial x_{j}}}
$$

where

$$
p_{1 j}=-p \delta_{1 j}+\frac{I}{2} \lambda e_{\ell \ell} \delta_{1 j}+\mu e_{1 j},
$$

and

$$
\begin{aligned}
& \delta_{1 j}=\left\{\begin{array}{ll}
1 & 1=j \\
0 & 1 \neq j
\end{array},\right. \\
& e_{i j}=\frac{\partial \bar{u}_{1}}{\partial x_{j}}+\frac{\partial \bar{u}_{1}}{\partial x_{i}},
\end{aligned}
$$

In the above, $\mu$ and $\lambda$ are the first and second coeffictents of viscosity.

The goal of this research has been to obtain a turbulence representation that is universal in applicability; Indeed these equations have been applied with success to a variety of turbulent flow studies. Gezerally, these studies have required the solution of transport equations for all components of the Reynolds stress, $\overline{\rho u_{i}^{T} u_{j}^{p}}$ (except those that would tend to vanish due to probled symmetries) as well as for the turbulence energy dissipation rate, $\frac{1}{2}\left(\frac{\partial u_{i}^{\prime}}{\partial x_{j}}\right)^{2}$. The solution of such a large set of complicated equations is very time-consuming, so that in eng1neering applications one would hope to make use of the experience gained in these studies while confinIrg his attention to a simpler system of equations. In the fireball study the turbulence representation is obtained from the solution of a eingle transport equation for the turbulence energy, $p q$, together with a specified scale, $B$, of the energy-carrying surbulent eddies. In the following section we show how the turbulence energy equation is derived and how the effects of turbulence are incorporated into the mean flow equations.

The turbulence energy per unit volume is defined by the relationship,

$$
\overline{p q}=\frac{1}{2} \overline{p u_{R}^{\prime} u_{R}^{\prime}} .
$$

whlle the general1zed Reynolds stress tensor, $R_{1 j}$ " 19 approximated by 
$\overline{\rho u_{i j}^{\prime} u_{j}^{\prime}}=\left(\frac{2}{3} q+\frac{1}{3} \sigma \overline{e_{\ell l}}\right) \bar{p} \delta_{i j}-\sigma \bar{\rho} \overline{e_{i j}}$

where $\sigma=\sigma(q, s)$ is the turbulent kinematic viscosity. Notice that, on contraction of indices, Eq.

(9) reduces to Eq. (8).

Various moments of fluctuating quantities appear in Eqs. (4), (5) and (6). In approximating these terms, we w111 make extensive use of the scalar flux approximation, 5

$$
\overline{Q^{\prime} u_{i}^{\prime}}=-\sigma \frac{\partial \bar{Q}}{\partial x_{i}},
$$

where $Q$ is any scalar quantity. Using this approximation and dropping the overbars, we can write the basic equations to describe the mean flow and the turbulence as:

mass equation -

$\frac{\partial \rho}{\partial t}+\frac{\partial}{\partial x_{j}}\left(\rho u_{j}\right)=\frac{\partial}{\partial x_{j}}\left(\sigma \frac{\partial \rho}{\partial x_{j}}\right)$

momentum equation -

$$
\begin{aligned}
\frac{\partial}{\partial t}\left(\rho u_{i}\right) & -\frac{\partial}{\partial t}\left(\sigma \frac{\partial \rho}{\partial x_{i}}\right)+\frac{\partial}{\partial x_{j}}\left(\rho u_{i} u_{j}\right)=\rho g_{i} \\
& +\frac{\partial}{\partial x_{j}}\left[P_{1 j}-\frac{2}{3} \rho\left(q+\frac{1}{2} \sigma e_{k k}\right) \delta_{1 j}+\rho \sigma e_{i j}\right. \\
& \left.+\sigma\left(u_{i} \frac{\partial \rho}{\partial x_{j}}+u_{j} \frac{\partial \rho}{\partial x_{i}}\right)\right]
\end{aligned}
$$

internal energy equation -

$\frac{\partial \rho I}{\partial t}+\frac{\partial \rho u_{i} I}{\partial x_{j}}=p_{i j} \frac{\partial u_{i}}{\partial x_{j}}+\frac{100 \rho \sigma g}{s^{2}}+\frac{\partial}{\partial x_{j}}\left(\sigma \frac{\partial \rho I}{\partial x_{j}}\right)$,

turbulence energy equation -

$$
\begin{aligned}
\frac{\partial \rho q}{\partial t} & +\frac{\partial}{\partial x_{i}}\left(f u_{i} q\right)=-\frac{\sigma}{\rho} \frac{\partial \rho}{\partial x_{1}} \frac{\partial p}{\partial x_{i}}+\rho \sigma e_{i j} \frac{\partial u_{i}}{\partial x_{i}} \\
& +\frac{\partial}{\partial x_{i}} \sigma \frac{\partial \rho q}{\partial x_{i}}-\frac{1}{3} \rho e_{k k}\left(q+\frac{1}{2} \sigma e_{\ell \ell}\right)-\frac{100 \rho \sigma q}{s^{2}} .
\end{aligned}
$$

In the above

$$
\sigma=0.02 \mathrm{~s} \sqrt{2 q}
$$

A detailed list of the symbols used is included in App. A.

An assumption which is made in the derivation of this model is that there exists a state of equilibrium among eddies of all sizes. We assume, in other words, that the time taken to equilibrate the cascade process, by which energy is transferred from the largest edcies where it is created to the smallest eddies where it is dissipated, is small compared to the times that matter in the problem. Current estimates for this equilibration time in fireballs vary from perhaps one-tenth to one torus formation tIme, but these numbers are uncertain.

\section{PARAMETERS OF THE MODEL}

In calculations with this model, it is necessary to estimate the size of the integral scale; that is, the size of the energy-carrying turbulent eddies. We use a phenomenclogical form fitted to the experiments of Wy gnanski and Fiedler, ${ }^{6}$ who measured the scale and the mean and fluctuating velocity profiles in turbulent free jets. We fit their data wath the expression,

$$
s(r, z)=0.14 d(z)\left\{\begin{array}{l}
2-\frac{v^{\prime}(r, z)}{v(0, z)}, v(r, z)>0 \\
2, v(r, z) \leq 0,
\end{array}\right.
$$

where $d(z)$ is the radial distance at a given 7 . froin the axis to the point at which the vertical component of valocity, $v(r, z)$, changes sign. This is approximately the radius to the point of maximum amplitude of yorticity. The scale has its minimum on the axis and rises to a maximum where $v(r, z)$ vanishes.

Its magnitude varies from perhaps $1 / 20$ th to $1 / 5$ th $\mathrm{km}$ over the fireball. An alternative to this empirical approach ts the use of a transport equation for the decay tensor, $D_{i j}$.

Figures 2 and 3 give an indication of the effect of the scale on the turbulence energy. These figures show the variation with time of the maximum and total turbulence energy, respectively. In both cases the dashed curve was calculated with a constant scale, $s=0.1 \mathrm{~km}$ while the solid curve was obtained with a simplified version of the phenonenol $\sim$ cal scale discussed above. 


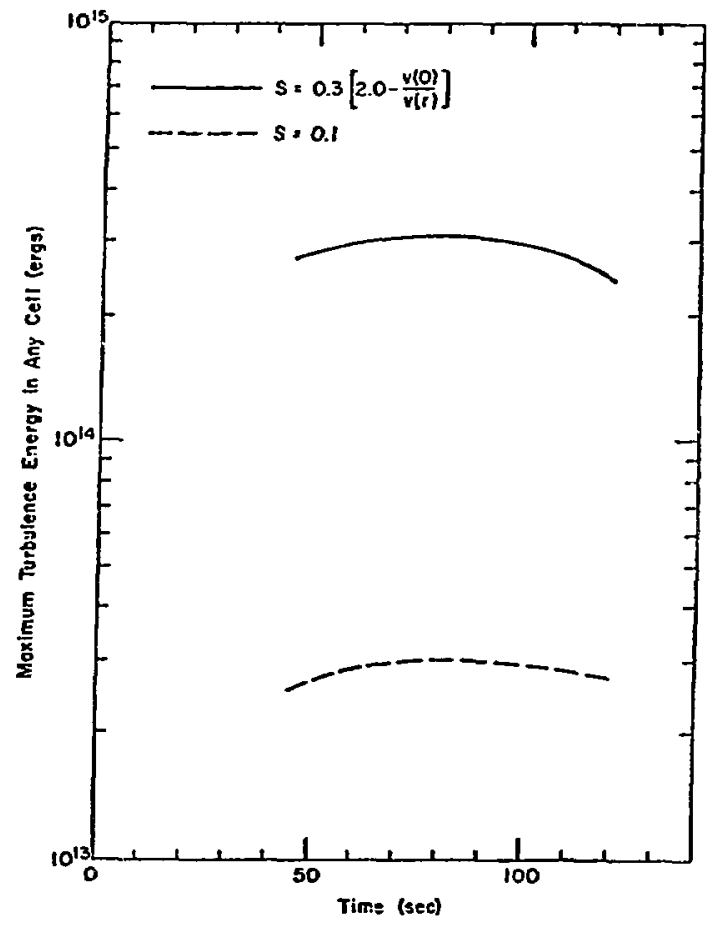

Fig. 2. Maximum turbulence energy in calculations with two different integral scale expressions.

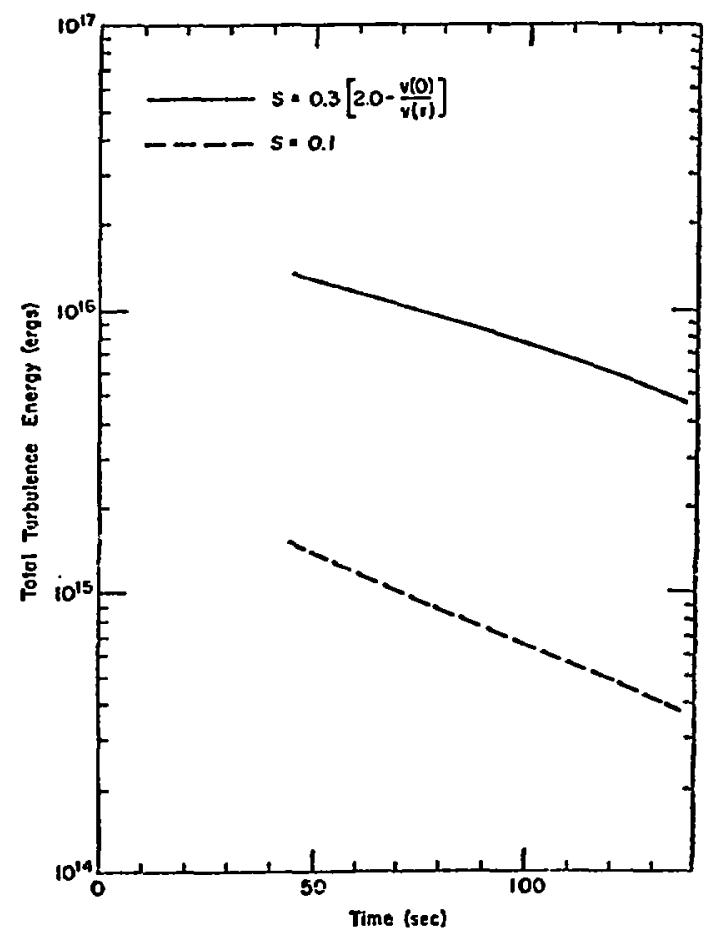

Fig. 3. Total turbulence energy obtained in calculations with different integral scale expressions.
The scales differ by about a factor of 3 and the energies by roughly an order of magnitude. One can argue that this is a consistent picture by equating the creation and decay at steady state. Since the creation is proportional to o $Y$ mean flow quantities and the decay is proportional to $\sigma q / \mathrm{s}^{2}$, one has

$$
\sigma A=\sigma B q / s^{2},
$$

where $A$ and $B$ are combinations of constants and mean flow quantities. If then the mean flow is roughly independent of the scale, this results in

$$
q \sim s^{2}
$$

This argument is to be taken cnly as an indication of the order of the effect of the scale on the turbulence energy. In the phenomenological scale calculation shown in Fig. 3, the total turbulence energy is about $1 \%$ of the total kinetic energy of the flow.

It is interesting to note that the rise altitude, as defined by the position of the cell with the maximum internal energy, is little affected by changes in the scale. Figure 4 displays the altitude as a function of time for two scale expressions. The $x$ 's were obtained with a scale $50 \%$ larger than those of the solid curve. Yet, at $210 \mathrm{sec}$ there is only a $1 / 2 \mathrm{~km}$ difference in height. There appears to be no difference in the two calculations for times less than $75 \mathrm{sec}$. Indeed, this last point has been a consistent finding in all of our calculations. We find that the turbulence has virtually no effect on dimensional data at less than $75 \mathrm{sec}$ and only a slight effect thereafter. This conclusion may depend on the expression for o that we are using, but nevertheless seems to indicate quite strongly that the effects of turbulence on the overall dynamics are relatively slight, within apparently reasonable ranges of the parameters involved. 


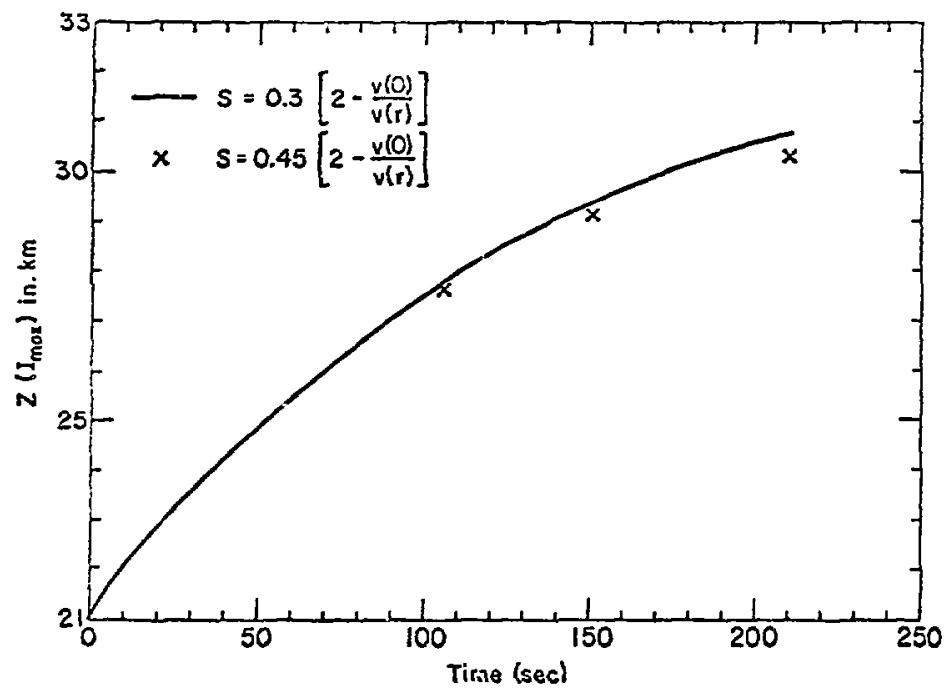

Yig. 4. Altitude as a function of time for two scales, one $50 \%$ larger than the other.

Although there is general agreement in models of this type that $\sigma$ may be expressed as $\sigma=\beta s \sqrt{2 q}$, the values of $B$ differ among the vartous investigators. We currently use a value of $\beta=0.02$, whtch value is based on the work of Launder, Mrse, Rodi, and Spalding. ${ }^{7}$ They compared stx turbur lence models in the prediction of free shear flows. In the model tinat they call the Prandtl energy model, they define a turbulence viscosity that is analogous to the above expression for $\sigma$ and in comparison with experiment they arrive at the value for $\beta$ that we are currently using. We then performed an independent check by testing this result against the channel flow studies of Laufer, ${ }^{8}$ and found that a value of $B=0.02$ produced good agreement between the turbulence model and the experimental measurements.

Another point that must be addressed is the seeding of the Initial turbulence. From the equation for the turbulence energy it is clear that in order to generate turbulence, it is necessary that some turbulence be already present. In the real firebal1, hydrodynamic Instabllities may serve to initiate the turbulence. In our numerical simulations, we must seed the turbulence in some appropriate way.
Figure 5 demonstrates that the magnitude and distribution of turbulence at late time is essentially independent of the wethod and level of seeding. Contour plots of the turbulence energy are displayed for two rather different seedings: In the upper plots the seeded turbulence was proportional to the mean flow vorticity field, while in the lower plots it was proportional to the mean kinetic energy at the same time. Clearly the two methods of seeding yleld marked differences in level and configuration initially, but by $30 \mathrm{sec}$ they have coalesced into a single distribution. What has happened is that the turbulence has decayed away in regions that cannot support it and has grown in those placed where shear and buoyancy create it. 


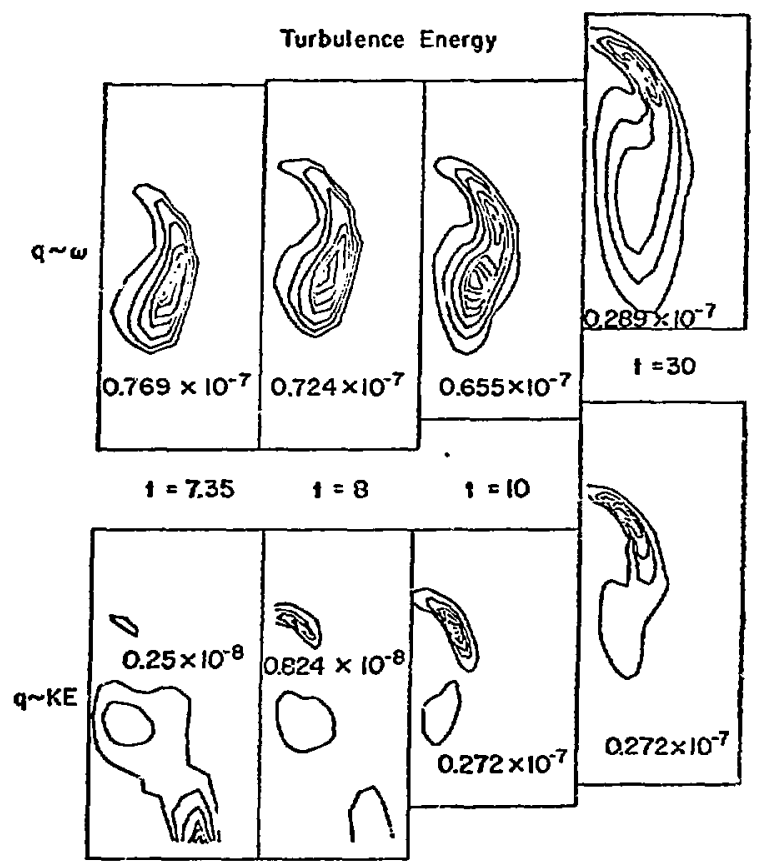

Fig. 5. Turbulence energy contours and maximum turbulence energy for four times with two different intial distributions.

Figure 6 indicates how local the shear creation, In fact, is; the same is true of the buoyancy creation. Moreover, the region of largest shear and buoyancy creation is at the upper edge of the fireball, which is also the region of steepest temperature gradients. One might expect then that the turbulence would reduce the maximum gradients and that is indeed what we find. Figure 7 shows a comparison of the maximum gradient of internal energy calculated with and without turbulence. Both of these were carried out with a fine grid and indicate what is probably the major effect of turbulence: the degrading of temperature and density gradients.

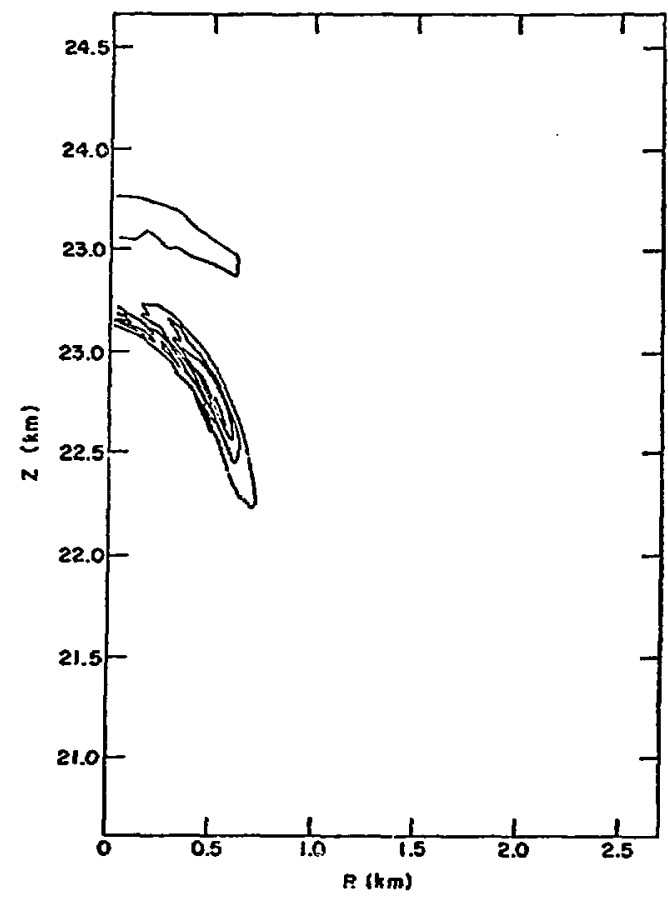

Fig. 6. Contour plots of shear creation.

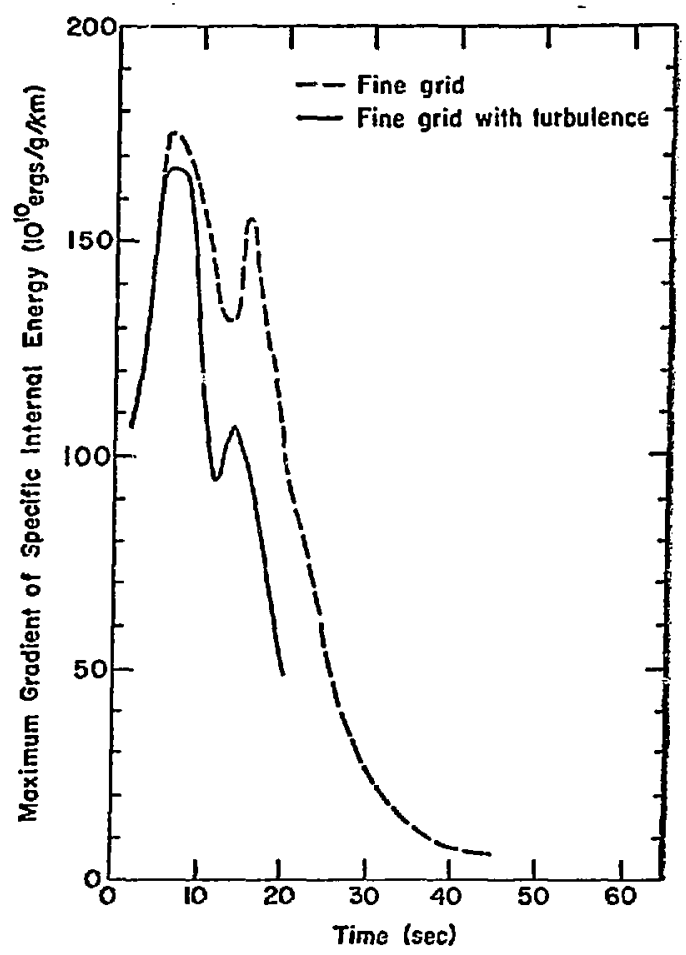

Fig. 7. Maximum gradient of internal energy w.th and without the inclusion of turbulence. 
One can see the effect of resolution on turbulence energy by comparing contour flots from a calculation with high resolution with one of low resolution in Fig. 8. The fine grid calculation has a maximum turbulence energy $50 \%$ greater than the coarse grid result on the right. The total turbulence energy differs by about the same ratio. Since the minimum cell size in the two calculations differs by a factor of $21 / 2$ and the turbulence energy by only $50 \%$, it is reasonable to assume that further refining of the average calculation zone size will not greatly affect the level of turbulence energy. Note also that the configurations of the two calculations in Fig. 8 are similar to appearance.

Figure 9 displays a rise history for typical calculations with and without turbulence. The inclusion of the added viscosity due to turbulence causes only a slight decrease in altitude at late times. It is, however, conceivable that as better calculations with sharper gradients are performed, higher levels of turbulence may be supported, which increase the net effect. In addition, a larger value of $B$ would likely lead to more pronounced differences due to turbulence.

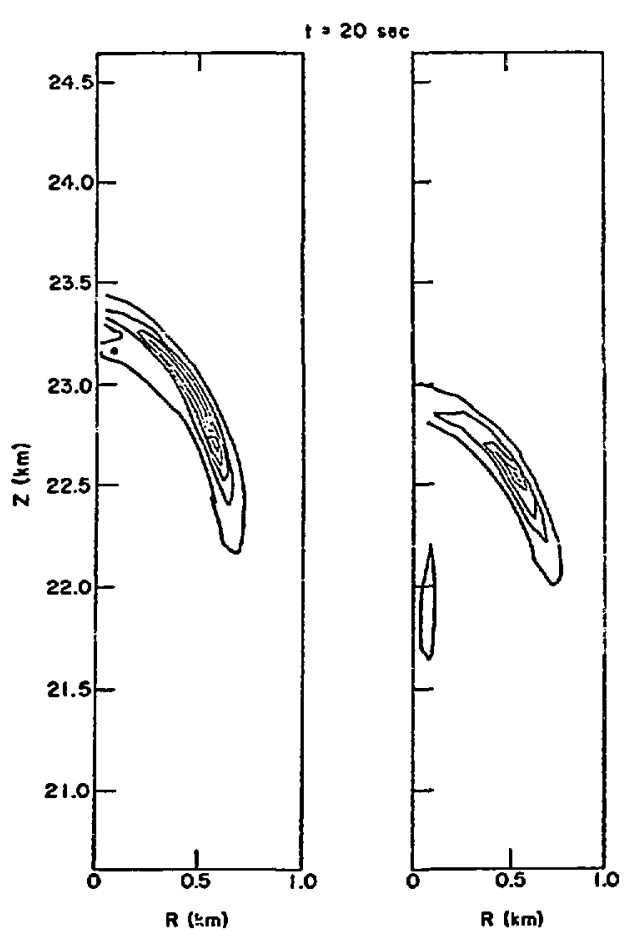

Fig. 8. Contour plots of turbulence energy for fine grid (left) and coarse grid (right) calculations.

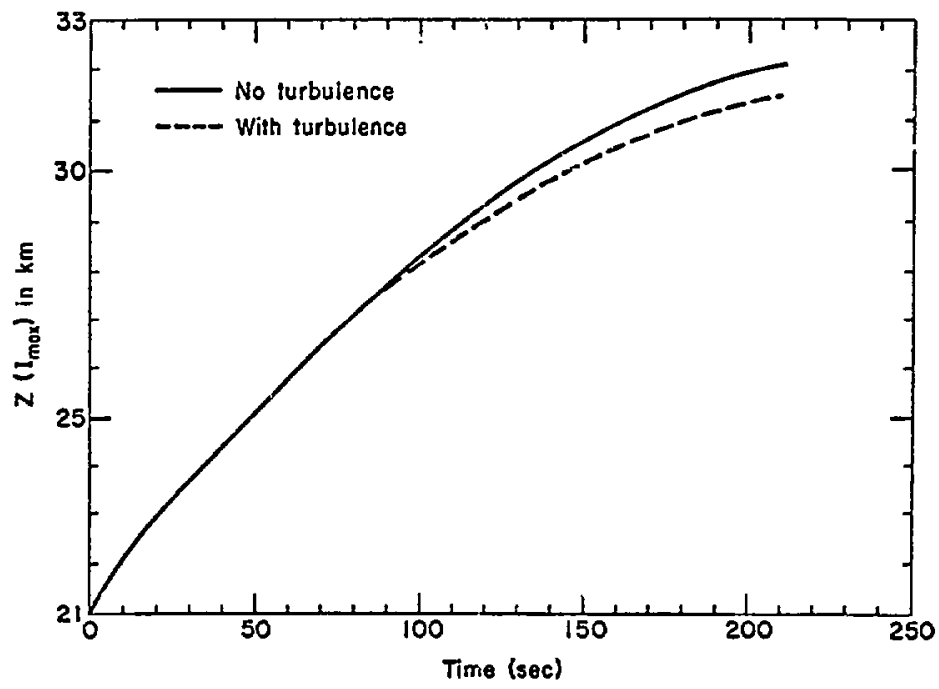

Fig. 9. Altitude as a function of time with and without the inclusion of turbulence. 
Work continues in an effort to improve agreement with experiment. Several events are being etudied concurrently, particularly to evaluate the agreement between the calculated and the measured radii. It appears that there are still uncertainties concerning the position of the edge of the firebal: that may be resolved by a clearer interpretation of the relation between the experimental data and the numerical simulations. He also continue to refine the turbulence model and to study the sensitivity of its predictions to the parameters we include. These are just a $f e w$ of the many aspects of the whole simulation effort with which we are concerned. Our primary goal remains to obtain a model that consistently predicts the dimensional behavior (rise altitude, radius, etc.) of a variety of low altitude atmospheric events.

\section{ACKNOWLEDGMENTS}

The authors are Indebted to Eric M. Jones for many helpful discussions of the whole field of low altitude fireball phenomenology.

\section{REFERENCES}

1. A. A. Amsden and C. W. Hirt, "YaQUI: An Arbitrary Lagrangian-Eulerian Computer Progran for Fluid Flows at All Speeds," Los Alamos Scientific Laboratory report LA-5100. March 1973.

2. C. W. Hirt, "An Arbitrary Lagrangian-Eulcrian Computing Technique," Froceedings of the Sccond International Conference on Mumerteal Methods in Fluid Dynamics, Berkeley, CA (1970).

3. E. M. Jones; private communication.

4. H. M. Ruppel, R. A. Gentry, and E. H. Jones; LASL, "Calculations of Low Altitude Fircbalis Using the Iced-Ale Nethod," presented at the DNA Low Aleicude Syeposium, April 1973.

5. B. J. Daly and F. H. Harlow, Phys. Flufds 13, 2634 (1970).

6. I. Hygnanski and H. Ficdler, J. Eluid Mech. 38, 577 (1969).

7. B. E. Launder, A. Morse, W. Rodt and D. B. Spalding, "The Prediction of Free Shear FlowsA Comparison of the Performance of S1x Turbulence Models," Imperial College Report M/TH/D/19 May 1972.

8. J. Laufer, NACA Repore No. 1053 (2951).

\section{NOTATION}

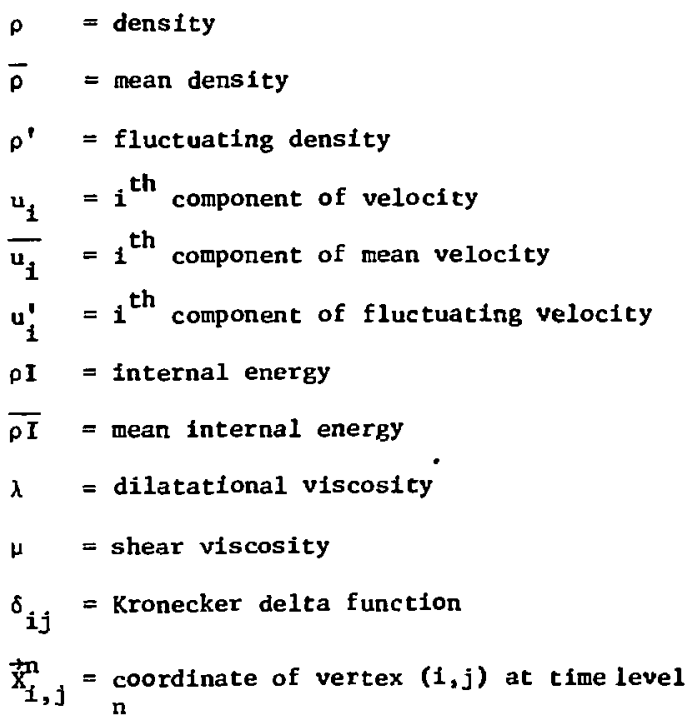

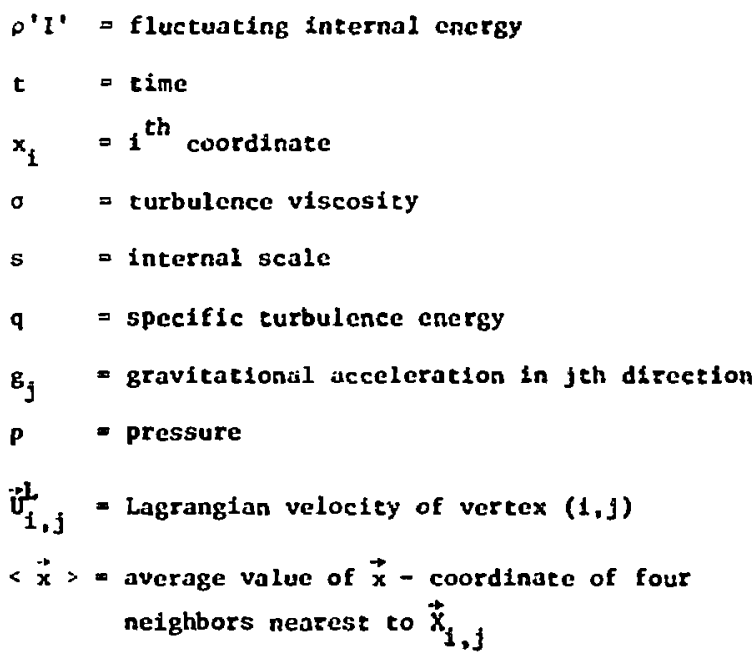

